IFAS Extension

\title{
Facts About Fluoride ${ }^{1}$
}

Anne Kendall ${ }^{2}$

\section{Why Do We Need Fluoride?}

Fluoride is important for healthy bones and teeth. It increases the density of bones and also can stimulate the growth of new bone. Fluoride increases the amount of minerals in our teeth and even can reverse the progression of dental cavities.

\section{What Happens If We Don't Get Enough Fluoride?}

People who don't get enough fluoride have much greater rates of dental decay and cavities than those who get enough fluoride. Due to water fluoridation, almost one-half of American children have never had a cavity in their permanent teeth.

Because of this success, water fluoridation has been called one of the ten great public health achievements of the twentieth century. Water fluoridation is especially important for children who do not have access to dental care. Recent research indicates that topical use of fluoride in toothpaste may be sufficient to prevent dental cavities. Groups at increased risk for developing dental cavities are those with lower incomes or less education with limited access to dental care.

We must get enough vitamin $\mathrm{D}$ and calcium in our diets so that fluoride can be incorporated into our teeth and bones. For information about these two important nutrients, see FY207/FCS8640 Facts About Vitamin D (http://edis.ifas. ufl.edu/fy207) and FY216/FCS8703 Facts About Calcium (http://edis.ifas.ufl.edu/fy216) in this series.

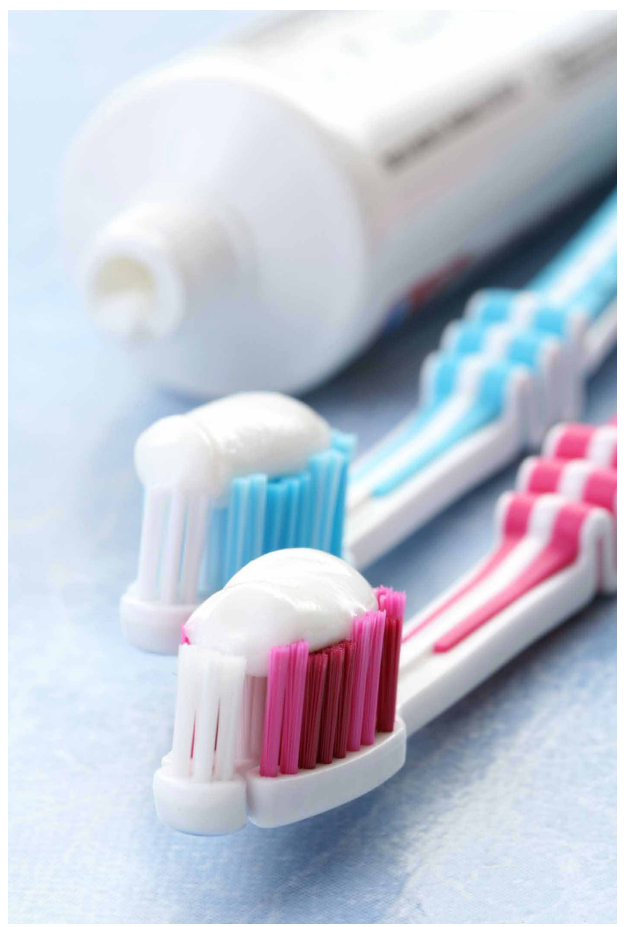

Figure 1. Using toothpaste with fluoride is an effective way to get fluoride to help prevent dental cavities.

Credits: iStockphoto

1. This document is FCS8798, one of a series of the Department of Family, Youth and Community Sciences, UF/IFAS Extension. Publication date: July 2006. Latest revision: July 2013. Please visit the EDIS website at http://edis.ifas.ufl.edu.

2. Anne Kendall, PhD, RD, LD/N, senior lecturer, Food Science and Human Nutrition Department; UF/IFAS Extension, Gainesville, FL 32611. 


\section{How Much Fluoride Do We Need?}

Table 1.

\begin{tabular}{|l|c|}
\hline Life Stage & Amount \\
\hline Children 7-12 mos. & $0.5 \mathrm{mg}^{*}$ \\
\hline Children 1-3 & $0.7 \mathrm{mg}$ \\
\hline Children 4-8 & $1.0 \mathrm{mg}$ \\
\hline Children 9-13 & $2.0 \mathrm{mg}$ \\
\hline Children 14-18 & $3.0 \mathrm{mg}$ \\
\hline Men, ages 19+ & $4.0 \mathrm{mg}$ \\
\hline Women, ages 19+ & $3.0 \mathrm{mg}$ \\
\hline & \\
\hline
\end{tabular}

\section{How Can I Get Enough Fluoride?}

Tap water has become the primary source of fluoride in the United States because of the increased fluoridation of community water supplies. Frequent use of topical agents such as toothpastes and mouthwashes containing fluoride are important for maintaining high dental fluoride concentrations. Children and adults at high risk for dental cavities may benefit from additional sources of fluoride such as mouth rinses, topical gels, or dietary supplements, and should check with their doctor for recommendations.

Check with your local water company for the amount of fluoride in your drinking water. If you have a home water filtration system, be sure to check with the manufacturer because many systems may remove fluoride from tap water. Also, if you frequently drink bottled water, be aware that most brands do not contain added fluoride.

Most foods contain little fluoride. Foods usually contribute only 0.3-0.6 milligrams of fluoride each day. Fish eaten with the bones, such as canned sardines or canned salmon, are higher in fluoride than most other foods. A three-ounce serving of canned sardines has about 0.3 milligrams of fluoride. An eight-ounce glass of brewed tea may contain 0.2-1.4 milligrams of fluoride, depending on the source of water used.

\section{How Much Is Too Much?}

Children who get too much fluoride will have teeth that look stained or "mottled." This is cosmetic and has no effect on the health of the teeth. Children should be taught to brush properly and to never swallow toothpaste, mouthwash, or fluoride rinses.
Very high intakes of fluoride for periods greater than 10 years can cause pain and stiffness in joints. It also causes abnormal hardening of the bones that can result in fractures. The upper limit for fluoride for children older than eight years and adults is $10 \mathrm{mg} /$ day.

\section{Where Can I Get More Information?}

The Family and Consumer Sciences (FCS) agent at your county UF/IFAS Extension office may have more information or nutrition classes for you to attend. Also, a registered dietitian $(\mathrm{RD})$ can provide reliable information. The American Dental Association has publications about fluoride and other information available on its website (http://www.ada.org).

Reliable nutrition information may be found at the following sites:

- UF Department of Family, Youth and Community Sciences: http://fycs.ifas.ufl.edu

- American Dental Association: http://www.ada.org

- UF/IFAS Extension: http://www.solutionsforyourlife.ufl. edu

- Nutrition.gov: http://www.nutrition.gov 